\title{
Structural Equation Modeling of Mental Toughness Among University Learners
}

\author{
Anatalia N. Endozo ${ }^{1}$ \\ ${ }^{1}$ Physical Education, College of Education, Angeles University Foundation, Philippines \\ Correspondence: Associate Professor Anatalia N. Endozo, Physical Education, Angeles University Foundation, \\ Philippines Mc Arthur Highway, Angeles, Pampanga 2009, Philippines. Tel: 63-921-597-2101. E-mail: \\ solomon467@gmail.com
}

Received: February 11, 2019 Accepted: February 24, 2019 Online Published: April 1, 2019

doi:10.5539/gjhs.v11n4p149

URL: https://doi.org/10.5539/gjhs.v11n4p149

\begin{abstract}
Background: Mental toughness is recognized as an important component towards academic success thus making its psychological qualities determine how challenges are effectively addressed during pressurized situations. Challenges facing undergraduate learners in the context of mental toughness had been broadly investigated mostly in developed countries. Most of the studies centered on sports and descriptive findings lack critical analysis.

Objective: The main objective of the current study was to investigate the level of mental toughness of university learners and the impact on the learners' academic performance. The current study also investigated whether university learners who were reported with greater mental toughness are more likely to be academically successful than those lower in mental toughness.

Methods: This quantitative study employed SmartPls 3 software to predict the significant level of motivation, self-reliance, concentration and coping with pressure on academic performance among university learners. Two universities were considered for assessing the structural equation modeling of mental toughness. Additionally, sources of data included reviews of different books on the related topics, research studies, articles, journals, newspapers, and magazines. Substantial information has been gathered from these sources thus allowing for appropriate analysis, compilation, interpretation, and structuring of the entire study. Thus, in an attempt to isolate and categorize potential attributes of mental toughness and its impact on academic performance, the available literature reviewed. This quantitative study considered adoptable in handling bias findings. A sample size of 417 considered appropriate for a variance based structural equation modeling. A total number of 417 responses gathered from Angeles University Foundation (AUF) and Baliuag University (BU), Philippines considered for this mental toughness study.
\end{abstract}

Results: A total of a 75 percent from the questionnaires (477) returned from a sum 600 questionnaires distributed to specified respondents. Demographic details report that female responded with round-off $60 \%$, this implied that female strive more in education than male. Ages 17-20 occupied 55\% nursing/medicine marked around of 34\% to top among the six colleges investigated in this study, next was college of business and administration marked around of $20 \%$ to take second place. This study suggested that students considered more to be medical doctors, professional nurses and business practitioners in the future rather than being professional teachers or system engineers. Reliability and validity of this study reported according to the Smart-Pls algorithm factor matrix, Cronbach's alpha, rho_A, and composite reliability all above 0.7 thresholds. Also, the average variance extracted from 0.5 achieved. The discriminant validity of this study based on Fornell-Lackner criterion, factor loading at 0.6 above and Heterotrait Monotrait Ratio quality achieved. Conclusively, all supported path coefficients significant at the p-values $<0.01$. In a nutshell, partial least squares algorithm reported about a $58 \%$ variance explained from the entire structured model.

Conclusion: The adopted factors for this structural equation modeling of mental toughness for university learners achieved fifty-eight percent variance explained in the study. Future studies can be directed towards replicating the use of this model in other locations and different analytical techniques.

Keywords: mental toughness, structural equation modeling, SmartPls 3, university learners, Philippines 


\section{Introduction}

Mental toughness considered as a psychological way in which individuals reacts in a difficult situation and quickly recovered. Learners, who are mentally tough, suggested not only be highly resilient in stressful conditions and coping with the kind of stresses, but flourish in them (Nicholls, Polman, Levy, \& Backhouse, 2008; Podrigalo, Iermakov, Rovnaya, Zukow, \& Nosko, 2016), studies justified confidence and coping with pressure are among the pillars to develop mental toughness model. Gucciardi, Gordon, and Dimmock (2008) adopted personal construct psychology as a framework to create a grounded theory of mental toughness.

The study stated that individuals strive to make sense of themselves and their environment, differ on how they cope with situations and interpret their confidence. From practical and applied point of view, it is imperative to understand how to build and develop mental toughness. Although there are on-going researches and debate as to exactly how mental toughness is developed. Connaughton, Hanton, and Jones (2010) an extended study about the theory of mental toughness among athletes and various career stages, the study supported the impact of confidence, motivation and coping with stress are aids to the development and maintenance of mental toughness.

On the other hand, Bull, Shambrook, James, and Brooks (2005) the study adopted competitiveness, tough attitudes, extra mindset and robust self-reliance as factors towards the development of tough character. The study justified robust self-reliance significant in the study. Valiente, Swanson, and Eisenberg (2012) reported that there has been little research about mental toughness among the university learners and its positive effect on academic success. Similarly, Qualter, Whiteley, Morley, and Dudiak (2009) stated that the development of emotional intelligence higher education student may be influenced by their level performance and confidence. This study focused on providing a structural modeling equation of mental toughness among university learners.

\section{Materials and Methods}

This is quantitative based study, employed SmartPls 3 software to predict the significant level of motivation, self-reliance, concentration and coping with pressure on academic performance among university learners. Two universities were considered for assessing the structural equation modeling of mental toughness. Additionally, sources of data included reviews different books on the related topics, research studies, articles, web portals, public websites, various journals, newspapers, and magazines, as well as different printed materials (brochures, etc.) collected from them. Substantial information has been gathered from these sources thus allowing for appropriate analysis, compilation, and interpretation and structuring of the entire study. Thus, in an attempt to isolate and categorize potential attributes mental toughness and its impact on academic performance, the available literature reviewed (Endozo, 2013).

A quantitative study is adaptable in handling bias findings (Hair, Sarstedt, Pieper, \& Ringle, 2012; Sheridan, Coakes, \& Peta, 2006; Ayodele et al., 2016). A sample size of 417 considered appropriate for a variance based structural equation modeling. A total number of 417 responses from two Angeles University Foundation (AUF) and Baliuag University (BU) in the Philippines considered for this mental toughness study. Nevertheless, this study also put the geographical location of the students into thought and selected tertiary educational institutions that could be used to justify the scope of the study as the suggested universities were approved for mental toughness assessment. Instruments generated are based on the previous related studies and 5-Likert scales applied to the questionnaire.

The principal component analysis, factor loading accomplished as all loaded at expected column, AVE above .5, composite reliability and all cronbach's alpha of 0.7 , p-values of .05, achieved (Hair et al., 2012; Oluyinka et al., 2013; Ayodele et al., 2018). Bootstrapped value and partial least square multiple weights $\left(\mathrm{R}^{2}\right)$ to explain the variance of the model adopted as recommended (Hair et al., 2012). Based on the reviewed, ability to coping with pressure, motivation, self-confidence, and concentration may have an imperative attributes to achieve mental toughness among university learners suggested in this study. Nevertheless, hypothetical regression paths of the study base on established attributes of mental toughness illustrated in Figure 1. 


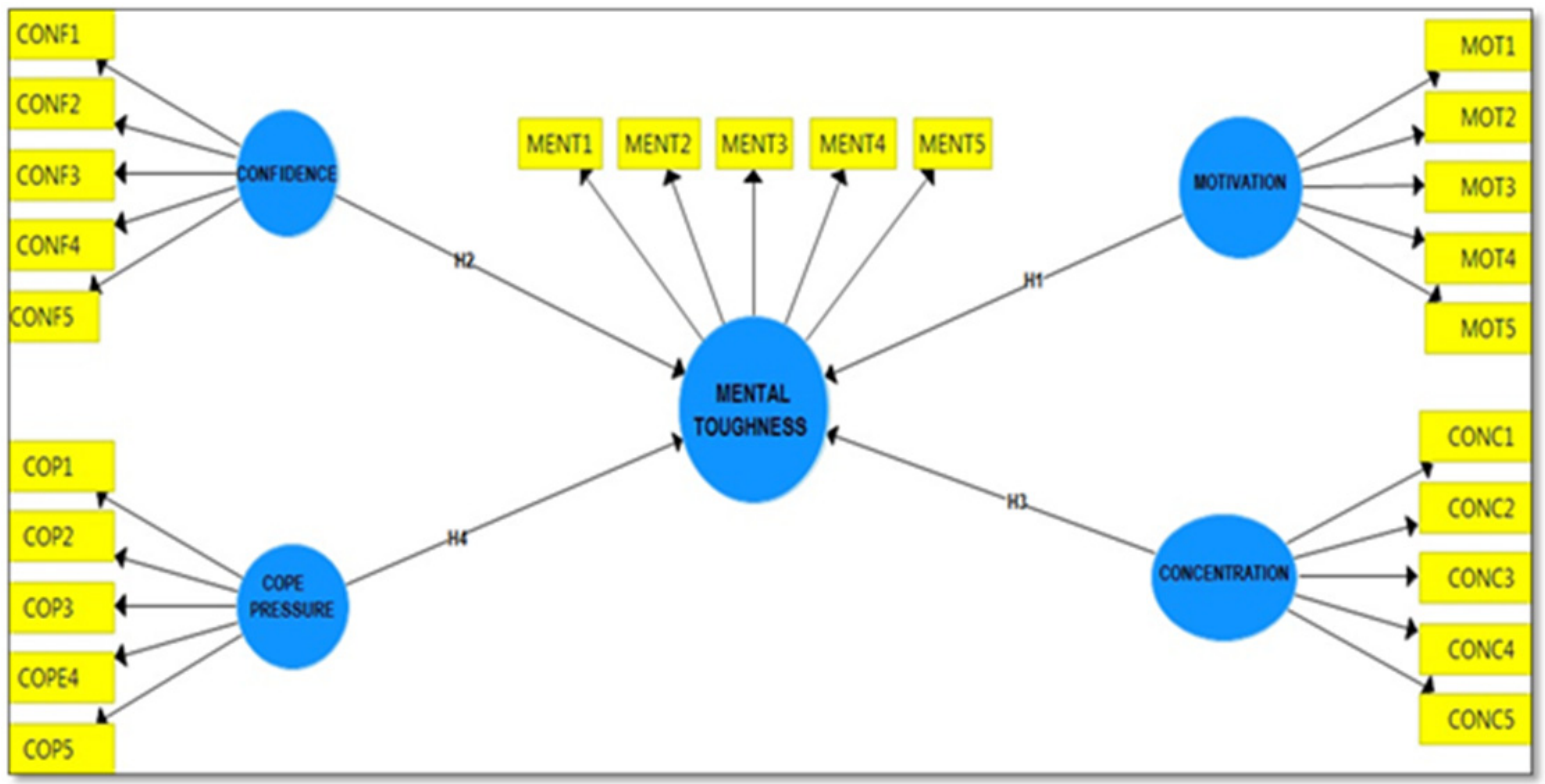

Figure 1. Hypothetical regression paths

After pre-examination of the measurements, thus structured the model in SmartPls 3.0 version, data analysis and details were presented. Furthermore, this study described the adopted variables in Table 1 of this study.

Table 1. Description model items used

\begin{tabular}{|c|c|c|c|}
\hline \multicolumn{3}{|c|}{ MOTIVATION } & \multirow{2}{*}{$\begin{array}{l}\text { COPING WITH PRESSURE } \\
\text { I know how to cope effectively with adversity }\end{array}$} \\
\hline MOT1 & I have the strong desire for success & $\mathrm{COP} 1$ & \\
\hline MOT2 & I have the willingness to push oneself & $\mathrm{COP} 2$ & I stayed calm under pressure \\
\hline MOT3 & I persist and work hard & COP3 & I belief anxiety is inevitable and enjoying it \\
\hline MOT4 & I know how to set difficult but attainable goal & $\mathrm{COP} 4$ & I thrive on pressure \\
\hline MOT5 & $\begin{array}{l}\text { I know how to bounce back from performance } \\
\text { attacks }\end{array}$ & COP5 & Generally, I can cope with pressure \\
\hline \multicolumn{3}{|c|}{ SELF CONFIDENCE } & MENTAL TOUGHNESS \\
\hline CONF1 & I have the abilities to achieve the goal & MENT1 & I belief in controlling things emotionally \\
\hline CONF2 & $\begin{array}{l}\text { I have strong belief in oneself to take educated } \\
\text { risks }\end{array}$ & MENT2 & I think am a goal getter and achiever \\
\hline CONF3 & I know how to learn from criticisms & MENT3 & I think my learning orientation seems high \\
\hline CONF4 & $\begin{array}{l}\text { I know how to control unwanted thoughts and } \\
\text { feelings }\end{array}$ & MENT4 & $\begin{array}{l}\text { I think in my abilities and inter-personal } \\
\text { confidence. }\end{array}$ \\
\hline CONF5 & I can handle unexpected situation in the future & MENT5 & I belief in seeing and seizing opportunities \\
\hline \multicolumn{4}{|c|}{ CONCENTRATION } \\
\hline $\mathrm{CONC1}$ & $\begin{array}{l}\text { Focus attention on the relevant cues in the } \\
\text { environment }\end{array}$ & & \\
\hline CONC2 & I know how to maintain focus despite distractions & & \\
\hline CONC3 & Never allow detraction from my priorities. & & \\
\hline CONC4 & I am focus on controlling the controllable. & & \\
\hline CONC5 & $\begin{array}{l}\text { I learn how to stay in the moment and focus on } \\
\text { positives }\end{array}$ & & \\
\hline
\end{tabular}




\subsection{Discriminant validity}

The discriminant validity of this study based on Fornell-Larckner criterion, factor loading at 0.6 above and Heterotrait Monotrait Ratio quality achieved. However, Figure 2 indicated the Heterotrait Monotrait Ratio quality of the constructs structured in this study after outliers and unsupported items discarded.

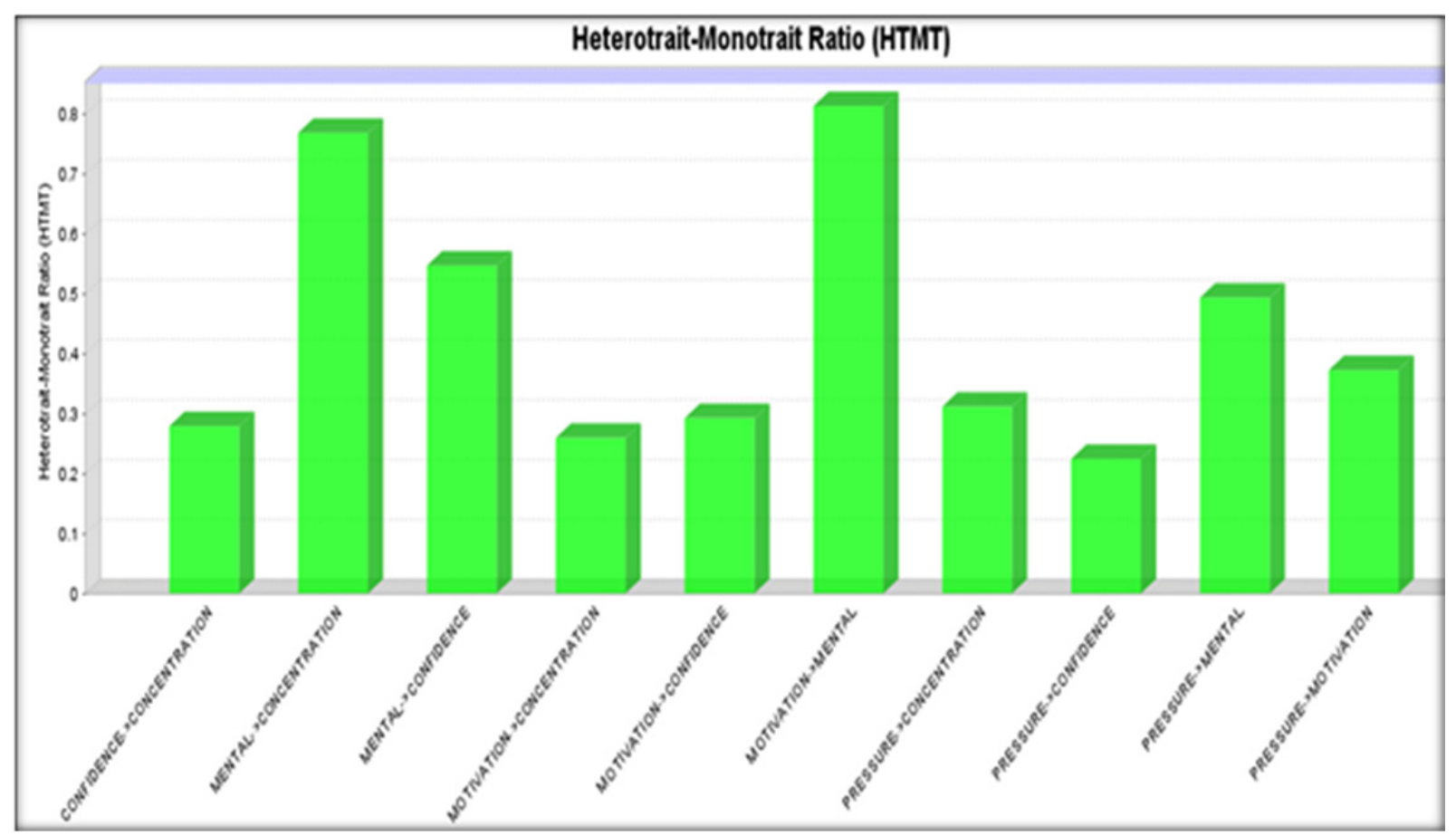

Figure 2. Discriminant Validity Based on Heterotrait-Monotrait Ratio

\subsection{Path Coefficients via Bootstrapping}

All validated samples bootstrapped to justify the statistical significance of various PLS-SEM results such as path coefficients, f-square, r-square and p-values. Table 3 indicated path coefficients such as sample means, standard deviation, t-statistics and p-values achieved in this study.

Table 4. Indicated path coefficients

\section{Path Coefficients}

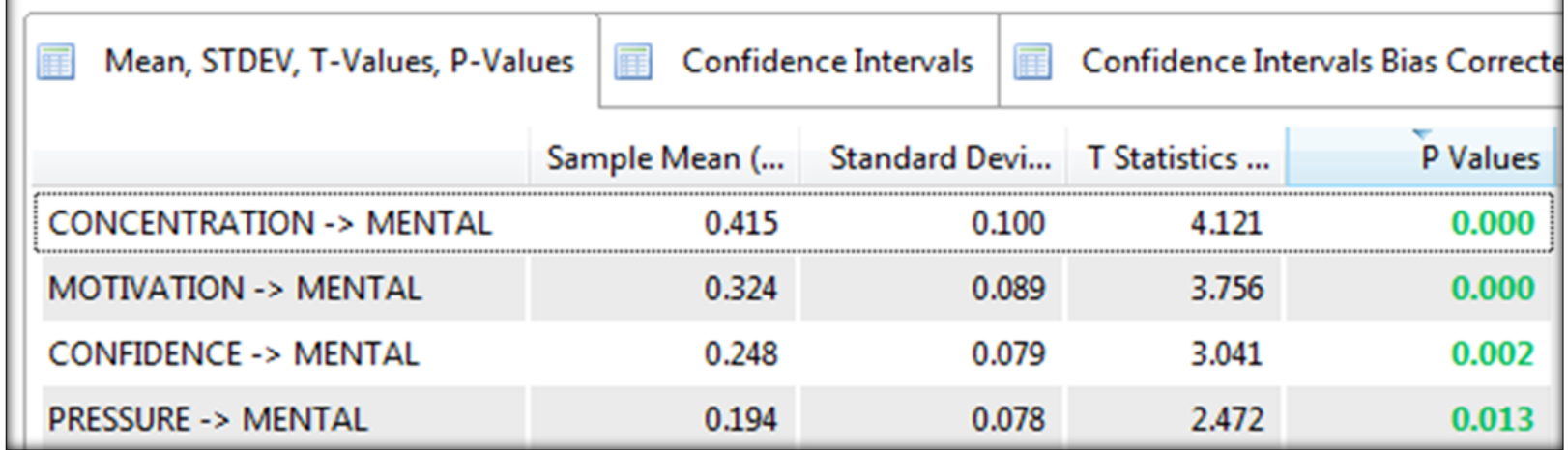

Furthermore, the Inner model path coefficients and constructs r-square of $58 \%$ achieved illustrated in Figure 3 of this study 


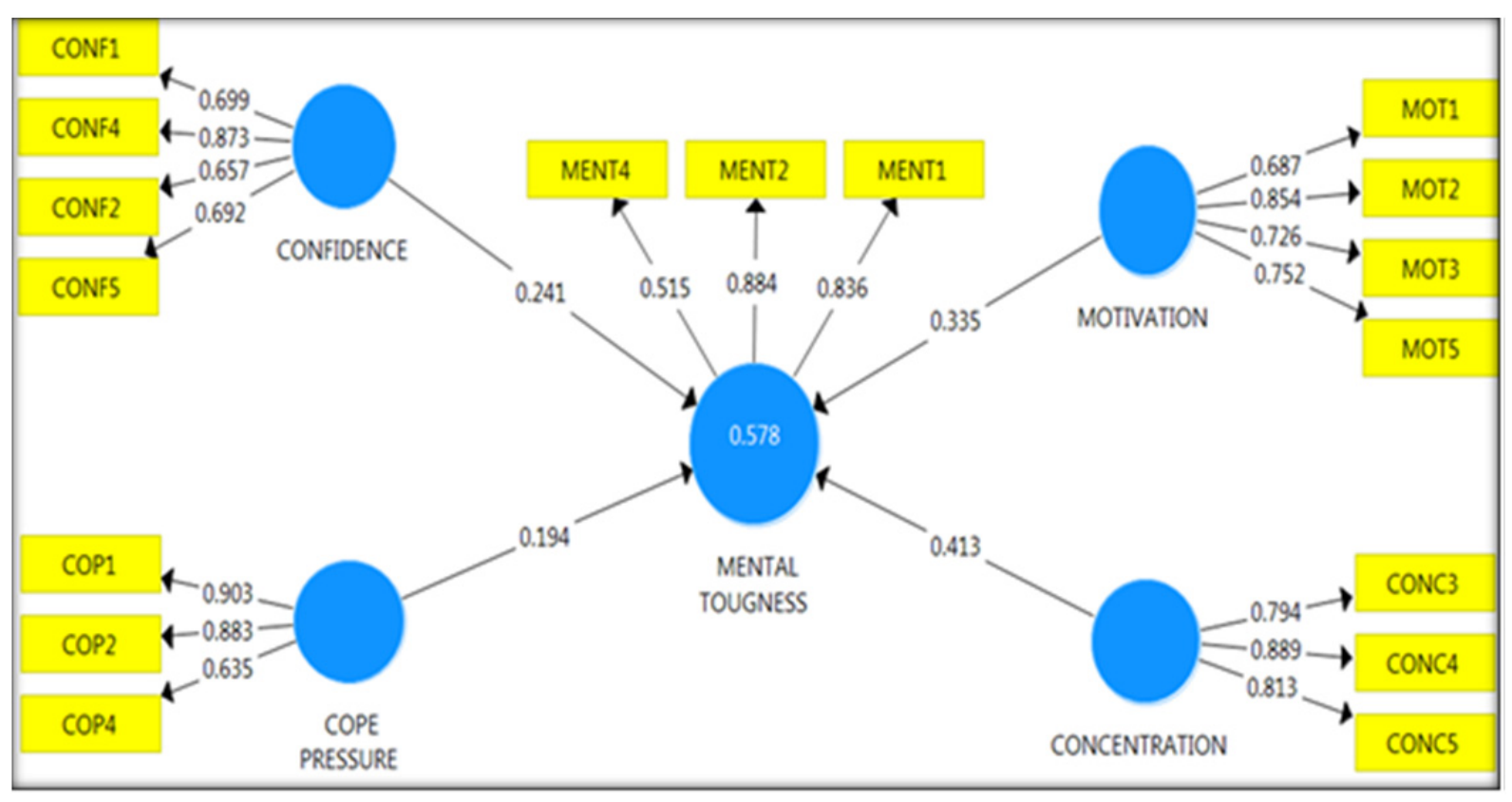

Figure 3. Mental Toughness Inner Path Coefficients and R-Square

Moreover, adopted independent variables and their significant factor loading described as followed; motivation constructs (MOT1: strong desire for success, MOT2: willingness to push oneself, MOT3: persist and work hard and MOT5: performance attacks). Self-confidence constructs (CONF1: abilities to achieve the goal, CONF 2: strong belief in oneself to take educated risks, CONF4: know how to control unwanted thoughts and feelings, and CONF5: can any handle unexpected situation). Concentration (CONC3: never allow detraction from my priorities, CONC4: focus on controlling the controllable, and CONC5: learn how to stay in the moment and focus on positives). Coping with pressure (COP1: I know how to cope effectively with adversity, COP2: stayed calm under pressure, and COP4: thrive on pressure) found significant on dependent variable (mental toughness) constructs (MENT1: I belief in controlling things emotionally, MENT2: I think am a goal-setter and achiever, and MENT4: I think in my abilities and inter-personal confidence). All factors loading loaded at expected column and above 0.6 as illustrated Figure 3 of this study.

Meanwhile, decisions towards the hypotheses developed that motivation, confidence, concentration and coping with pressure may influence mental toughness among university learners justified with p-value less than .05 in this study. Conclusively, all supported path coefficients significant at $\mathrm{p}$-values $<0.01$. In a nutshell, partial least squares algorithm reported about a $58 \%$ variance explained from the entire structured model. Nevertheless, concentration suggested the most significant, followed by motivation, confidence and cope with pressure respectively supported attributes to mental toughness among the university learners the Philippines.

\section{Review Outcomes}

Jones, Hanton, and Connaughton (2007) established a useful practical framework towards designing mental toughness model. The significant attributes are motivation, self-confidence, attention focus, coping with pressure. From a practical perspective, these attributes had been broadly adopted to structure mental toughness in different context. Hence, studies related to the aforementioned four presented the next section of this study.

Motivation for the mentally tough individual would encompass a strong desire for success; willingness to push oneself, persist, and work hard; setting difficult but attainable goals; and bouncing back from performance setbacks (Butt, Weinberg, Breckon, \& Claytor, 2011; Bell, Hardy, \& Beattie, 2013). Bell et al.(2013) in the study enhancing mental toughness and performance under pressure, the study justified that mental toughness intervention effects general psychological skills, motivation effects regressed on punishment avoidance supported in the study. Mahoney, Gucciardi, Ntoumanis, and Mallet (2014) argued that basic psychological needs theory offers impetus to the value of mental toughness as a mechanism for optimizing human functioning. The study supported that psychological needs satisfaction could be associated with higher/lower levels of mental toughness. The study justified that mental toughness influences higher performance and lower levels of negative affect vice-versa. 
In addition, Machida, Ward, and Vealey (2012) emphasized on predictors of self-confidence, the study examine nine sources of confidence. Sources of confidence were categorized into controllable and uncontrollable. Previous researches indicated that controllable sources of confidence are critical for enduring levels of confidence. Machida et al. (2012) considered self-confidence as one of the most important mental toughness characteristics. This suggested that mentally tough individuals' have the abilities to achieve goals based on their confidence state of mind. Jones et al. (2007) stated that strong belief in oneself enables the mentally tough person to take educated risks, learn from criticisms, control unwanted thoughts and feelings, and expect that good things will happen in the future. Crust et al. (2014) supported that mental toughness sub scales of life control and interpersonal confidence were predictors of academic achievement of students.

Attention focus is the ability to attend to internal and external cues in your attention field. Prime focus involves focusing only on performance-relevant cues in your attention field. In other words, only focusing on cues that help you to perform your best (Gucciardi et al., 2008). Lohse and Sherwood (2011) the study presents two experiments designed to explore the effects of attention on perceived exertion and time to failure in a fatiguing athletic tasks. The study justified attention focus effects in endurance tasks and attention focus as external/internal. Crust et al. (2014) suggested that the use of appropriate cue words may aid task focus by increasing focus on task relevant stimuli and reduce mistakes and nervousness. Hardy (2006) suggests that the use of cue words may help individuals adjust their focus of attention towards a more appropriate attention focus for completion of tasks. It will also distinguish that the most appropriate type of attention focus will be dependent on the skill level of the performer and the type of task being performed.

Coping with pressure; Kaiseler et al. (2009) the study examined the relationship between mental toughness, stress appraisal, coping strategies and coping effectiveness. In support of a prior prediction, mental toughness was associated with stress intensity and control appraisal, but not the type of stress experienced Total mental toughness and its six components predicted coping and coping effectiveness in relation to the self-selected stress. In particular, higher levels of mental toughness were associated with more problem-focused coping, but less emotion-focused and avoidance coping. This pillar relates to being able to perform under pressure by controlling the amount and nature of stress experienced (Jones et al., 2007). The different aspects of pressure as it relates to mental toughness include coping effectively with adversity; staying calm under pressure; accepting that anxiety is inevitable and enjoying it; thriving on pressure; and interpreting anxiety as facilitative for performance (Gucciardi et al.,2008; Jones et al., 2011;Connaughton, 2002 and Weinberg et al., 2011).

Conducting further studies on mental toughness could suggest that students in higher educational institutions demonstrating higher levels of mental toughness may be more goal focused and less susceptible to negative emotional behaviors and this may have a positive impact on academic outcomes. Consequently, the aim of the current study is to investigate whether university learners who report to have greater mental toughness are more likely to be academically successful than those lower in mental toughness. It is also the aim of this study to gain further insights into the structural equation modeling of mental toughness and its impact on academic success.

Supportively, several studies validated and foretell precise strength of mental toughness features besides other psychological factors aforementioned within the concepts and considered ideals among other theories of mental toughness most centered on the physical education and sports. Accordingly, assumed noted factors could be re validated on university learners in respective of the disciplines.

Based on supporting studies related to mental toughness, thus, presents the hypothetical statements based on the designed framework for this study in figure 1. Further, studies including (Butt, Weinberg, Breckon, \& Claytor, 2011; Bell, Hardy, \& Beattie, 2013; Mahoney, Gucciardi, Ntoumanis, \& Mallet, 2014) affirmed motivation influences mental toughness that mental toughness influences higher performance and lower levels of negative affect vice-versa. Reference to the previous studies, this current study replicated that motivation has influences on mental toughness towards academic performance as first hypothesis for this study. Crust et al. (2014) and Machida et al. (2012) self-confidence is one of the most important attributes of mental toughness. Based on established studies, replicated self-confidence has influences on mental toughness towards academic performance as second hypothesis for this study. Higher performance-relevant to focus and your attention (Gucciardi et al., 2008), level attention has significant relationship with performing certain task (Lohse and Sherwood, 2011). Crust et al. (2014) increasing focus on certain task reduces nervousness. Based on these established studies, replicated concentration has influences on mental toughness towards academic performance as third hypothesis for this study.

Kaiseler et al. (2009) there is relationship between mental toughness, stress appraisal, coping strategies and effectiveness towards achievement, aspects of pressure affects mental toughness (Gucciardi et al., 2008) ability to withstand pressure maybe influence mental toughness towards a particular task (Jones et al., 2011) and inability to 
interpret anxiety may affect performance (Weinberg et al., 2011). Based on these established facts, replicated coping with pressure has influences on mental toughness towards academic performance as fourth hypothesis for this study. All suggested hypotheses channeled towards structural equation modeling of mental toughness for university learners.

This is a quantitative based study, employed SmartPls to predict attributes of mental toughness among Angeles University Foundation and Baliuag University students in the Philippines. A quantitative study is adoptable in handling studies using instrument like questionnaire (Creswell and Creswell, 2017; Hussein, 2015). A sample size of 100 above considered appropriate for a variance based structural equation modeling (Hair et al., 2017; Henseler et al., 2012).

A total number of 417 responses from two universities (AUF and BU) in the Philippines utilized. This study also put the area of discipline of the students into consideration, thus selected students on their $4^{\text {th }}$ and above year level from the college of education, business administration, medicine, nursing, art and sciences, engineering, computer and information in AUF and BU considered as the participants of this study.

Instruments generated are based on the previous related studies and 5-Likert scales applied on the questionnaire, motivation construct comprises of five, coping with pressure comprises of five items, confidence five items and attention constructs with five items as well. Thus, have five constructs with five items each. Thus, a total number of 25 measurement items considered for further analysis in this study.

\section{Partial Least Squares Algorithm}

The PLS path modeling method adopted, the Partial Least Squares Algorithm PLS which is a sequence of regressions in terms of weights(Dijkstra, 2010).This was performed to identify the quality of the items used.

\section{Quality of the measurement model}

Construct reliability and validity, identifying the ability of the instrument adopted were very important to have quality measurement (Hair et al., 2012). These were achieved at 0.7 above achieved for each construct. Likewise rho_A at 0.7 above achieved. Also to confirm the reliability of the study, composite reliability at 0.7 achieved. In addition average variance extracted at 0.5 above for each construct achieved.

Discriminant validity was also performed. The quality based on Fornell-Larckner criterion, factor loading achieved at 0.6 above achieved. Hetero trait Mono trait Ratio achieved below 0.8. However, details of the analysis will be discussed in the subsequent section.

Bootstrapping is a non parametric procedure that allows testing the statistical significance of various PLS-SEM results (Hair et al., 2017). This was performed to justify the path coefficients, F-square, R-square and p-values.

\section{Discussion}

This study presents a standpoint on the structural equation modeling of mental toughness and how the critical attributes of mental toughness contribute to academic success by sampling participants from university learners. The foremost intention of this study was to take a look at the degree of mental toughness of university learners based on the four critical attributes of mental toughness discovered from previous mentioned studies. The attributed investigated found significant included motivation, confidence, concentration and coping with pressure towards academic performance of university learners in the Philippines, this study affirmed mental toughness study could be investigated different field of study apart from sports point of view.

Concentration was found out to be the highest rank that contributes to achieve and maintain the level of mental toughness. With this, it was concluded that university learners do not allow things to detract their attention from priorities and know how to stay focus on positives in any given time. This study agreed mental toughness among the university learners that if learners allowed in terms of focusing on controlling the controllable areas of studies, then their performance will be highly improved.

Furthermore, this concluded study discovered motivation as one of the most important attributes towards mental toughness among the university learners in the Philippines. The respondents identified to have a strong desire for success as manifested with their persistence to work hard and they know how to bounce back from performance tasks. However, this study indicated that learners have strong willed and determination to push themselves to have better academic position. This study suggested that mental toughness among the university learners may be further developed through internal and external motivation.

In addition, this study dealt with self-confidence aspects of the learners as another attributes to mental toughness, it was found out that the university learners have a strong belief of themselves to take risks and challenges towards 
achieving positive academic performance. In general, the level of self-confidence towards mental toughness in this study justified that the ability to control unwanted thoughts and feelings could be one of the best ways to obtain higher level of mental toughness among university learners that even differ from field sports and physical education learners.

With regards to coping with pressure among the university learners, this study indicated that learners can stay calm and thrive under pressure and can interpret anxiety as facilitative to performance, this study also affirmed that learners mental toughness can be achieved as in the act of coping effectively with adversity found to be most significant aspects of the construct in this concluded study. This implied that mental toughness can be developed through the act of understanding how to cope with pressures. Also noted that agreed anxiety is inevitable to an extent. At this point of our findings on coping with pressures in relation to maintaining the level of mental toughness as reflected on the lowest value level achieved in this study.

\subsection{Limitations}

The end results need to be used with attention because of small pattern dimension and we recruited solely selected university learners from third, fourth and fifth year levels. Age brackets adopted in this study may considered as one of the limitation to this study, because some students with same age noted in level two and not included in this study.

\section{Conclusion}

It can be concluded that this study is one of the few find out about that examined the stage of mental toughness among university learners in different colleges such as college of Nursing and Medicine, Education, Business and Administration, Arts and Sciences, Engineering and Information and Technology. The investigated levels included learners in year three to year five in mentioned colleges at Angeles University Foundation and Baliuag University in the Philippines.

Although, adopted attributes (that is motivation, confidence, focus and coping with pressure) had been established in different contexts. Nevertheless, this concluded study also supported that established factors towards mental toughness among college learners in the aforementioned academic field of studies differed from the field of sports and physical education

\section{Acknowledgments}

We are thankful to the Angeles University Foundation and Dr. Solomon Ayodele Oluyinka, Baliuag University for his personal contributions. We are also thankful to all the people who in one way or the other contributed in the completion of this study.

\section{Funding}

There was no fund for this study except library access support from the Angeles University Foundation and Baliuag University library.

\section{Competing Interests Statement}

All authors declare no conflict of interest.

\section{References}

Ayodele, S. O., Oga, O. E., Bundot, Y. G., \& Ogbari, M. E. (2016, October). Role of power supply towards e-learning acceptance: VBSEM-AMOS. In 2016 6th International Conference on Information Communication and Management (ICICM) (pp. 151-155). IEEE.

Ayodele, S., Endozo, A., \& Ogbari, M. E. (2018, October). A study on factors hindering online learning acceptance in developing countries. In Proceedings of the 10th International Conference on Education Technology and Computers (pp. 254-258). ACM. https://doi.org/10.1145/3290511.3290533

Bell, J. J., Hardy, L., \& Beattie, S. (2013). Enhancing mental toughness and performance under pressure in elite young cricketers: A 2-year longitudinal intervention. Sport, Exercise, and Performance Psychology, 2(4), 281. https://doi.org/10.1037/a0033129

Bull, S. J., Shambrook, C. J., James, W., \& Brooks, J. E. (2005). Towards an understanding of mental toughness in elite English cricketers. Journal of applied sport psychology, 17(3), 209-227. https://doi.org/10.1080/10413200591010085

Butt, J., Weinberg, R. S., Breckon, J. D., \& Claytor, R. P. (2011). Adolescent physical activity participation and motivational determinants across gender, age, and race. Journal of Physical Activity and Health, 8(8), 
1074-1083. https://doi.org/10.1123/jpah.8.8.1074

Connaughton, D., Hanton, S., \& Jones, G. (2010). The development and maintenance of mental toughness in the world's best performers. The Sport Psychologist, 24(2), 168-193. https://doi.org/10.1123/tsp.24.2.168

Crust, L. (2008). A review and conceptual re-examination of mental toughness: Implications for future researchers. Personality and individual differences, 45(7), 576-583. https://doi.org/10.1016/j.paid.2008.07.005

Endozo Larce, A. SELF TESTING AND FITNESS ACTIVITIES: An Instructional Modules for College AUF PE Students. In The Dubai International Conference in Higher Education 2013 (p. 292). Universal-Publishers.

Gucciardi, D. F., Gordon, S., \& Dimmock, J. A. (2008). Towards an understanding of mental toughness in Australian football. Journal of Applied Sport Psychology, 20(3), 261-281. https://doi.org/10.1080/10413200801998556

Hair, J. F., Sarstedt, M., Pieper, T. M., \& Ringle, C. M. (2012). The use of partial least squares structural equation modeling in strategic management research: a review of past practices and recommendations for future applications. Long range planning, 45(5-6), 320-340. https://doi.org/10.1016/j.lrp.2012.09.008

Hardy, L., Bell, J., \& Beattie, S. (2014). A neuropsychological model of mentally tough behavior. Journal of Personality, 82(1), 69-81. https://doi.org/10.1111/jopy.12034

Jones, G., Hanton, S., \& Connaughton, D. (2007). A framework of mental toughness in the world's best performers. The Sport Psychologist, 21(2), 243-264. https://doi.org/10.1123/tsp.21.2.243

Machida, M., Marie Ward, R., \& Vealey, R. S. (2012). Predictors of sources of self-confidence in collegiate athletes. International Journal of sport and exercise psychology, 10(3), 172-185. https://doi.org/10.1080/1612197X.2012.672013

Mahoney, J. W., Gucciardi, D. F., Ntoumanis, N., \& Mallet, C. J. (2014). Mental toughness in sport: Motivational antecedents and associations with performance and psychological health. Journal of Sport and Exercise Psychology, 36(3), 281-292. https://doi.org/10.1123/jsep.2013-0260

Nicholls, A. R., Polman, R. C., Levy, A. R., \& Backhouse, S. H. (2008). Mental toughness, optimism, pessimism, and coping among athletes. Personality and individual differences, 44(5), 1182-1192. https://doi.org/10.1016/j.paid.2007.11.011

Oluyinka, S., Shamsuddin, A., Ajabe, M. A., \& Enegbuma, W. I. (2013). A study of electronic commerce adoption factors in Nigeria. IJISCM, 6(4), 293-315. https://doi.org/10.1504/IJISCM.2013.060974

Qualter, P., Whiteley, H., Morley, A., \& Dudiak, H. (2009). The role of emotional intelligence in the decision to persist with academic studies in HE. Research in Post Compulsory Education, 14(3), $219-231$. https://doi.org/10.1080/13596740903139255

Sheridan, J., Coakes, L. S. \& Peta, D. (2006). SPSS 13.0 for windows. Analysis without anguish. National Library of Australia.

St Clair-Thompson, H., Bugler, M., Robinson, J., Clough, P., McGeown, S. P., \& Perry, J. (2015). Mental toughness in education: Exploring relationships with attainment, attendance, behaviour and peer relationships. Educational Psychology, 35(7), 886-907. https://doi.org/10.1080/01443410.2014.895294

Valiente, C., Swanson, J., \& Eisenberg, N. (2012). Linking students' emotions and academic achievement: When and why emotions matter. Child development perspectives, 6(2), 129-135. https://doi.org/10.1111/j.1750-8606.2011.00192.x

\section{Copyrights}

Copyright for this article is retained by the author(s), with first publication rights granted to the journal.

This is an open-access article distributed under the terms and conditions of the Creative Commons Attribution license (http://creativecommons.org/licenses/by/4.0/). 